https://helda.helsinki.fi

Challenges in using administrative enforcement measures in local food control

Kettunen, Karoliina

2017-06

Kettunen , K , Nevas , M \& Lunden , J 2017 , ' Challenges in using administrative enforcement measures in local food control ' , Food Control , vol. 76 , pp. 34-41 . https://doi.org/10.1016/j.foodcont.2

http://hdl.handle.net/10138/308934

https://doi.org/10.1016/j.foodcont.2017.01.002

cc_by_nc_nd

acceptedVersion

Downloaded from Helda, University of Helsinki institutional repository.

This is an electronic reprint of the original article.

This reprint may differ from the original in pagination and typographic detail.

Please cite the original version. 
1 Challenges in using administrative enforcement measures in local food control

2

3 Karoliina Kettunen, Mari Nevas and Janne Lundén

4 Department of Food Hygiene and Environmental Health, Faculty of Veterinary Medicine, P.O. Box 566,00014 University of Helsinki, Finland

6

7

8

9

10

18 Corresponding author: Karoliina Kettunen, Department of Food Hygiene and Environmental

19 Health, Faculty of Veterinary Medicine, P.O. Box 66, 00014 University of Helsinki, Finland

20

e-mail address: karoliina.r.kettunen@helsinki.fi 


\section{Keywords \\ Keywords}

\section{Abstract}

We surveyed Finnish local food control officials' opinions about the use and challenges of administrative enforcement measures. Responses to the questionnaire were received from a total of 129 food control officials, covering $72.6 \%$ of the 62 local food control units in Finland. In the opinion of $42.7 \%$ of the respondents, enforcement measures are not used often enough in their unit to ensure food safety. Based on our results, large units have better practical tools such as templates for enforcement decisions and guidelines that facilitate the use of enforcement measures than small units, but uncertain practices and a lack of routine appear to impede the use of the measures in many units. Particular challenges highlighted by the officials were related to laboriousness and slowness of the administrative process and reasoning for using enforcement measures. Moreover, impairment of cooperation with the food business operator as a consequence of using enforcement measures was of concern for many officials. The officials assessed the expertise of the head of the unit more positively in the units in which enforcement measures were used than in the units in which enforcement measures were not used, and participation in trainings was the strongest explanatory factor for the use of enforcement measures among the inspectors. Our results indicate that development of operating procedures and provision of specific training on administrative procedure with a practical approach play a key role in strengthening officials' expertise and confidence in using enforcement measures. Moreover, merging the small units with the large ones may promote uniform practices and better capabilities to use enforcement measures in all units.

Enforcement measures; official food control; administration; efficacy; uniformity

\section{Introduction}


Prevention of foodborne illnesses by verifying food business operators' (FBOs) compliance with food safety regulations requires effective, risk-based and impartial official food control. If the FBOs, despite the advice, guidance and requests of the authorities, do not comply with food safety regulations, authorities shall take effective actions to ensure that food safety violations are corrected (EC No 882/2004; Food Act, 2011). These actions, called administrative enforcement (coercive) measures (hereafter referred to as "enforcement measures"), may include such measures as imposition of sanitation procedures, restriction or prohibition of placing a food on the market, suspension of operation or closure of all or part of the business concerned (EC No 882/2004, Food Act, 2011). Efficient intervention in the case of non-compliance is essential not only for food safety but also for preventing distorted competition between compliant and non-compliant FBOs (Hampton, 2004).

To ensure that the same legislative requirements are effectively enforced for all FBOs, all food control authorities should have similar principles and prerequisites for using efficient control measures. In some European Union (EU) Member States, the need for more training and guidelines for authorities on enforcement procedures has been recognized (Lepistö \& Hänninen, 2011; European Commission, 2013). In the United Kingdom (UK) and in Finland, increased guidance has enhanced the use of enforcement measures (European Commission, 2013). Nevertheless, Finnish food control authorities' actions in cases of FBOs' non-compliances have been assessed as insufficient (FVO, 2014).

Previous studies have indicated that enforcement measures are effective in making FBOs correct their food safety violations (Kettunen, Nevas, \& Lundén, 2015). In the UK, several aspects, such as the size, resources and location of the local authority and the relationship between the official and the FBO, have been discussed to affect enforcement practices (Hutter \& Amodu, 2009). In Finland, administrative shortcomings in the enforcement process have been reported in local food control, probably due to officials' uncertainty concerning administrative procedures 
(Lepistö, Nevas, \& Hänninen, 2009; Lepistö \& Hänninen, 2011). Moreover, official veterinarians seem to have poorer expertise in administrative procedures in slaughterhouses showing more severe non-compliances than other slaughterhouses (Luukkanen \& Lundén, 2016). Despite relatively little research within this particular area, it seems that the characteristics of the control authority as well as food control officials' perceptions and knowledge may influence the use of enforcement measures, possibly leading to a situation where some authorities use enforcement measures when needed while others do not. This may result in unequal treatment of FBOs and, in the worst case, compromised food safety.

In Finland, enforcement measures can be used at the local level in 62 municipal food and environmental health control units (hereafter "units") consisting of one or more municipalities (Food Act, 2011). The units operate independently within their areas but are regionally guided by six Regional State Administrative Agencies. Nationally, official food control is coordinated and supervised by the Finnish Food Safety Authority Evira (Food Act, 2011). The jurisdiction to make enforcement decisions in the units lies within the municipal authority bodies, which are multimember bodies named by the municipalities within the control unit. The municipal authority bodies may delegate their jurisdiction to make enforcement decisions to the heads or inspecting officials of the units. In urgent cases of severe health hazard, all food control officials have the right to apply certain enforcement measures even if no jurisdiction is delegated within the unit (Food Act, 2011).

Municipal independence may generate differing practices and approaches in implementation of official food control. Many food safety requirements laid down in the EU and national food safety legislation allow case-dependent interpretation, thus, similar cases may result in different regulatory outcomes. The use of enforcement measures has been shown to vary among the units (Lepistö et al., 2009; Kettunen et al., 2015), and inconsistency has been reported also in other 
control procedures and inspection practices among the units and inspecting officials (Läikkö-Roto, Mäkelä, Lundén, Heikkilä, \& Nevas, 2015).

The aim of this study was to investigate the factors affecting the use of enforcement measures and related challenges in Finnish local food control units. The study was conducted through a survey exploring the current practices and perceptions of local food control officials and heads of control units regarding the use of enforcement measures. The results can be utilized in harmonizing official food control practices and developing enforcement procedures.

\section{Material and methods}

\subsection{Questionnaire}

We developed an electronic questionnaire (E-lomake, Eduix Oy) to explore the factors affecting the use of enforcement measures and to evaluate the perceptions of local food control units concerning the use of enforcement measures in food control. The questionnaire was designated for the heads and the inspecting officers (inspectors) of the local food control units $(\mathrm{n}=62)$ in Finland, and it was partly tailored depending on whether the respondent was a head of the unit or an inspector. Prior to conducting the survey, the questionnaire was piloted with a head of one unit and three inspectors from two units. The questionnaire was sent in September 2015, and a reminder was sent three weeks later.

The semi-structured questionnaire included Likert-scale questions and multiple-choice questions. In addition, open-ended questions allowed respondents to elaborate on their answers to closed questions or to freely state their opinions about the topics of the survey. The questionnaire inquired about background information on the unit (e.g. labour resources designated for food control and the number of food premises in the unit's area), delegation of jurisdiction regarding the use of enforcement measures and availability of internal guidelines and templates for enforcement 
decisions in the unit. If not indicated on the questionnaire, information about the labour resources of the unit and the number of food premises in the unit's area were collected from units' internet pages in cases where the information was publicly available. Respondents' education and opinions about the quality and adequacy of available training and national guidelines concerning enforcement measures were also requested. Furthermore, respondents were asked to assess the knowledge, skills and consistency of use of enforcement measures by themselves and in their unit.

\subsection{Quantitative and qualitative analyses of the data}

Data analysis was conducted by using quantitative dominant mixed methods, in which the priority is given to quantitative data, but elements of qualitative research are included to broaden and deepen the understanding on the research topic (Johnson, Onwuegbuzie, \& Turner, 2007). The units were divided into groups based on the use of enforcement measures within the last three years (hereafter "enforcer units" and "non-enforcer units"), number of labour resources for performing official food control tasks and the education of the head of the unit. Units with labour resources equal to or less than the median of the responding units were categorized as small, and units with labour resources greater than the median were categorized as large. The respondents were categorized based on whether they were the heads of the unit or inspectors. The inspectors were further divided into groups based on whether they had used enforcement measures themselves within the last three years or not (hereafter "enforcer inspectors" and "non-enforcer inspectors").

To compare factors affecting the use of enforcement measures in the units, such as availability of templates and guidelines, each unit was scored based on six factors (Table 1). Each factor gave the unit one point (positive response) or zero points (negative response), and the overall scores for each unit were calculated as a mean of the unit's total points. Units with missing information in more than two factors were excluded from scoring. A sum variable "knowledge" was 
created to compare the units based on their respondents' perceptions of their knowledge of using enforcement measures with respect to: a) food hygiene and safety, b) food safety legislation, c) administrative processes and d) whether it's clear when to use enforcement measures. The variables included in the sum variable were on a four-point Likert-scale $(1=$ fully disagree, $2=$ somewhat disagree, 3 = somewhat agree, $4=$ fully agree).

The statistical analyses of the data were carried out by using SPSS statistical software (IBM SPPS Statistics 22.0, NY, USA). As the variables used in the analyses appeared not to be normally distributed, non-parametric tests were used. The differences between enforcer and nonenforcer and large and small units in labour resources, number of food premises, scoring based on factors affecting the use of enforcement measures and sum variable "knowledge" were analysed with a two-tailed Mann-Whitney U test. Regional differences among the units in the scoring were analysed with Kruskal-Wallis test and in the use of enforcement measures with Pearson Chi-Square test. Fisher's exact test was used for comparison of groups with categorical variables, and Spearman's rho to examine the correlations between continuous variables. Cronbach's Alpha was used to examine the reliability of the created sum variable. To identify the variables of the units and inspectors explaining the use of enforcement measures among the enforcer and non-enforcer inspectors, a classification tree analysis based on the Chi-Squared Automatic Interaction Detection (CHAID) method, by using the likelihood-ratio Chi-Squared method due to the rather small sample size, was performed. By creating the possible cross tabulations for each defined independent variable (predictor), the CHAID analysis generates a classification tree model that illustrates how the independent variables best merge to explain the outcome in the given dependent (target) variable. The target variable was the use of enforcement measures by the inspector (yes/no), and the predictors included in the CHAID analysis were personal variables related to the inspectors (working experience in food control field and participation in a training regarding use of enforcement measures), inspectors' perceptions of the use of enforcement measures (Table 2) and 
variables related to control unit (availability of templates for enforcement decisions and urgent enforcement decisions, discussion on the use of enforcement measures in the unit, availability of an internal guideline for the use of enforcement measures, delegation of jurisdiction to use enforcement measures, availability of juridical assistance in the unit). The "I don't know" answers were categorized as missing in the analyses, and statistical significance was accepted with a confidence level of $95 \%$ (two-tailed $p$-values $<0.05$ ).

The responses to two open-ended questions were analysed by applying the procedure of content analysis described by O'Cathain and Thomas (2004). The two questions analysed were 1) "Is there something you perceive as problematic, difficult or laborious in the use of enforcement measures?" and 2) "Freely express your opinions about enforcement measures." The initial stages of the analysis, including familiarization with the data, manual coding of the answers and development of the initial themes, were conducted by one author independently. The identified themes and underlying codes were subsequently interpreted through discussions among all authors and a common agreement was achieved.

\section{Results}

\subsection{The respondents}

Responses $(\mathrm{n}=129)$ were received from altogether $72.6 \%(45 / 62)$ of the control units from the regions of all six Regional State Administrative Agencies in Finland. Regional response rates of the units ranged between $40.0 \%-88.9 \%$. Of the respondents, $28(21.7 \%)$ were the heads of the unit and $101(78.3 \%)$ were inspectors. A total of $86.7 \%(39 / 45)$ of the units and $61.4 \%(62 / 101)$ of the inspectors had used enforcement measures in the last three years. Of the non-enforcer units $(n=6)$, one head of the unit and a total of seven inspectors responded. No regional differences were observed among the units in whether enforcement measures had been used or not (Pearson Chi- 
191 Square $\mathrm{p}=0.878$ ). The median of the labour resources of the units was 4.0 person-years (range 1.0 19233.0 ) in respondent units and 2.1 person-years (range 1.4-7.2) in non-respondent units. Among the respondent units, the share of the small and large units was $57.9 \%(22 / 38)$ and $42.1 \%(16 / 38)$, respectively. All large units $(16 / 16 ; 100.0 \%)$ and $77.3 \%(17 / 22)$ of the small units had used enforcement measures. Among the inspectors $(n=101), 49.5 \%$ had a bachelor's degree, $36.3 \%$ a higher academic degree such as licentiate of veterinary medicine $(13.1 \%)$ or a master's degree in another field $(23.2 \%)$, and $14.1 \%$ had other education such as vocational education. The head of the unit had a veterinary education in $56.4 \%$ of the enforcer units, but in none of the non-enforcer units (Table 1).

3.2 Use of enforcement measures and factors affecting use in the units and among the inspectors

Among the enforcer inspectors, $83.8 \%$ (35/42) fully or partly agreed that the use of enforcement measures had improved food safety in food premises. However, $42.7 \%(47 / 110)$ of all respondents fully or partly agreed that enforcement measures are not used in their unit often enough to ensure food safety (Fig. 1). More than half of the respondents fully or partly agreed that food control authorities should more often report food safety violations to the police, and that the head of the unit should have a right to fine a FBO if severe food safety violations are observed (Fig. 1).

The overall scores of the units based on factors affecting the use of enforcement measures (median 0.67 , range $0.17-1.00$ ) were significantly higher in enforcer units than in nonenforcer units and in large units than in small units (Table 1). The scores of the units did not differ regionally (Kruskal-Wallis $\mathrm{p}=0.696$ ). With regard to the sole factors used in scoring the units, large units, compared with small units, had significantly more often templates for enforcement decisions and urgent enforcement measures and an internal guideline for the use of enforcement measures (Table 1). In addition, enforcer units had more often a positive response in all factors used 
in scoring the units compared with non-enforcer units, although the differences were not significant (Table 1). However, as many as $40.0 \%(40 / 100)$ of the respondents of the enforcer units fully or partly disagreed that their unit has routine practices in the use of enforcement measures, and certain practical tools needed for the use of enforcement measures were also lacking in many enforcer units. For instance, templates for urgent enforcement decisions were available in $38.9 \%$ of the enforcer units and in none of the non-enforcer units (Table 1). Moreover, an internal guideline for use of enforcement measures existed in about half (54.1\%) of the enforcer units and in only $33.3 \%$ of non-enforcer units (Table 1).

Among the inspectors $(n=101)$, participation in training regarding the use of enforcement measures within the last five years was the strongest explanatory factor for the use of enforcement measures in the CHAID analysis (Fig. 2). In addition, availability of templates for enforcement decisions in the unit and delegation of jurisdiction to use enforcement measures were also indicated as significant factors (Fig. 2). Of all respondents $(n=129)$, however, only $43.8 \%$ (49/112) considered available training for the use of enforcement measures as sufficient. Moreover, barely half of the respondents $(65 / 129 ; 50.4 \%)$ had utilized the national guideline for the use of enforcement measures, and only $52.3 \%(34 / 65)$ of these respondents perceived the guideline to be useful in practice.

According to $85.2 \%(23 / 27)$ of the heads of the units, municipal politicians had never attempted to affect the use of enforcement measures or particular enforcement decisions. However, four heads stated that the politicians or the members of the municipal authority body had seldom or occasionally tried to affect the decisions, for instance, by being in contact with the FBO or by questioning officials' assessments. In one open-ended answer, the head stated that the municipal authority body had given the FBO more time to correct the violations by postponing the decision rendered by the officials, although the FBO had operated without valid approval of the establishment. 

measures was available in $53.6 \%(15 / 28)$ of the units, all of which were enforcer units. In the opinion of $68.9 \%(82 / 119)$ of all respondents, lawyers acquainted with food legislation are needed in their unit.

A total of 53/101 inspectors (52.5\%) and 20/28 heads of the units (71.4\%) responded to the openended questions regarding their thoughts about enforcement measures and the difficulties and challenges in their use. Among the answers, five main themes were identified: 1) necessity of enforcement measures, 2) inefficiency of the process, 3) arduousness of the procedure, 4) uncertainty in the use of enforcement measures and 5) FBO-related challenges. Many respondents highlighted the importance and need of enforcement measures for efficient official food control ( $\mathrm{n}=$ 12), and two respondents stated that using enforcement measures is sometimes "the only choice" to get the non-compliance corrected. However, the slowness of the process $(n=14)$ and the lack of substantial consequences to a non-compliant FBO $(\mathrm{n}=7)$ were perceived to impair the effectiveness of the measures. Five respondents debated whether fining the FBO would be a more

256 efficient intervention. On the other hand, ten respondents considered negotiation with the FBO to be 257 a preferable option to get the non-compliance corrected.

Regarding the arduousness of the process, the administrative formalities associated with several stages, such as hearing the FBO regarding the decision, were perceived to be laborious and complex $(n=26)$ and time-consuming $(n=14)$. The main reasons for uncertainty in use of enforcement measures were the lack of routine or common practices $(n=17)$, and ten respondents highlighted the need for more training and guidelines, especially with a practical approach on the use of enforcement measures. Deciding on whether or not to initiate an enforcement process and 
which measure to apply $(n=10)$ as well as formulating and reasoning of the decisions $(n=19)$ were found to be problematic.

The most often mentioned FBO-related challenges concerned FBOs' lack of understanding of the enforcement decision or the requirements $(n=12)$ due to inadequate knowledge of food legislation or poor attitude towards compliance. Specifically, four respondents highlighted the existence of "cultural or language barriers" in communication with the FBOs, and four mentioned that the delivery of the decision to the FBO is often difficult due to the FBO's reluctance. Furthermore, among the inspectors, using enforcement measures was perceived to impair the cooperation between the inspector and the FBO significantly more often by the nonenforcer inspectors than by the enforcer inspectors (Fisher's exact test $\mathrm{p}=0.026$ ) (Table 2).

3.4 Inspectors' perceptions of their own and their superiors' expertise in using enforcement measures

A majority of both enforcer and non-enforcer inspectors perceived their own knowledge of food hygiene and safety and food safety legislation as sufficient for the use of enforcement measures (Table 2). However, the non-enforcer inspectors appeared to find their knowledge of the administrative process and their certainty about the use of enforcement measures as poorer than the enforcer inspectors, although the differences were not significant $(p=0.053$ and $p=0.088$, respectively) (Table 2). enforcer units assessed it as significantly more positively than the inspectors of the non-enforcer units. Almost all inspectors of the enforcer units fully or partly agreed that the head of their unit had sufficient knowledge of food hygiene and safety (83/86; $96.5 \%)$, food safety legislation (81/85; $95.3 \%)$ and administrative processes $(85 / 86 ; 98.8 \%)$. By contrast, among the inspectors of the non- 
enforcer units, the shares of fully or partly agreeing responses to these three sectors were $14.3 \%$ $(1 / 7), 33.3 \%(2 / 6)$ and $42.9 \%(3 / 7)$, respectively (Fisher's exact test $p<0.001, p<0.001$ and $p=$ 0.010 , respectively). The more positively the inspectors assessed the head's expertise in these three sectors, the more they agreed that they would get support from him/her in using enforcement measures (Spearman's rho $r=0.400, p<0.001 ; r=0.412, p<0.001$; and $r=0.455, p<0.001$, respectively). A comparison between the inspectors also indicated significant differences in their opinions of the expertise of the head of their unit based on the education of the head. All inspectors of the units in which the head was a veterinarian fully or partly agreed that the head of their unit had sufficient knowledge of food hygiene and safety $(56 / 56 ; 100.0 \%)$, food safety legislation (56/56; $100.0 \%)$ and administrative processes $(55 / 55 ; 100.0 \%)$, whereas in units in which the head was not a veterinarian, corresponding proportions were $75.7 \%(28 / 37), 77.1 \%(27 / 35)$ and $86.8 \%(33 / 38)$ (Fisher's exact test $\mathrm{p}<0.001, \mathrm{p}<0.001$ and $\mathrm{p}=0.010$, respectively).

\section{Discussion}

Almost half of the respondents perceived that enforcement measures are not used often enough in their control unit to ensure food safety. Based on our results, lack of routine and unclearly defined practices in the units appear to hinder the use of enforcement measures and its consistency both at the unit level and among the inspectors. Although most inspectors seem to perceive their knowledge of food hygiene and food safety legislation as sufficient for the use of enforcement measures, not all are confident with the enforcement procedure in practice. Particularly, certainty in deciding when enforcement measures should be used and knowledge of administrative procedures were more positively assessed by enforcer than non-enforcer inspectors. The lack of confidence and routine in the enforcement process may have had a restrictive effect on the non-enforcer inspectors' willingness to use enforcement measures, leading to non-use of enforcement measures even when 
312 their use is necessary. Officials' dissimilar knowledge about and preconditions for using 313 enforcement measures will presumably cause inequality among the FBOs.

Participation in trainings related to the use of enforcement measures was the strongest explanatory factor differentiating enforcer and non-enforcer inspectors in the CHAID analysis. Also at the unit level, the inspectors of enforcer units had more commonly taken part in trainings than inspectors of non-enforcer units. Despite the reported positive influence of the new guidelines and an increase in training on the use of enforcement measures (European Commission, 2013), the availability or utilization of the provided guidance still appears inadequate. As wished by many officials, more training with a practical approach and example cases, particularly for the nonenforcer inspectors, could be supportive in deciding which situations and which enforcement measures should be applied. Specifically, education on administrative procedure and formulating and reasoning of the enforcement decisions appears to be needed as officials found these issues to be problematic. To maintain and develop their professional skills, personnel's capability to participate in trainings should be ensured in all units. to have better prerequisites and practical tools, such as templates and internal guidelines, for using enforcement measures and are more likely to use enforcement measures than small units. Large units, compared with small units, may have better abilities to allocate labour and expertise for development of operational procedures within the unit, thus enhancing the use of enforcement measures. Internal guidelines and templates probably facilitate the use of enforcement measures by decreasing the time needed for the process and by unifying the practices within the unit. Simplifying and expediting the initiation of an urgent enforcement process are crucial in case of an immediate health hazard. Pre forma templates and checklists have previously been shown to enhance the quality and efficacy of restaurant inspections (Läikkö-Roto et al., 2015). The existence of operating procedures on paper does not, however, alone guarantee inspectors' commitment to 
joint practices, but the adoption of written guidelines requires well-functioning communication and opportunities to discuss the issues jointly (Läikkö-Roto, Lundén, Heikkilä, \& Nevas, 2016). Similar factors to those revealed in our study related to control authority's resources and officials' experience have also been reported to be challenges in the enforcement of e.g. environmental regulation (IMPEL, 2015). To share enforcer units' good practices and to mitigate the uncertainty in the use of enforcement measures in non-enforcer units, development of cross-audits and other forms of benchmarking among the units is recommended. In addition, merging the small units with the large ones could promote consistent practices and equal capabilities to use enforcement measures in all units.

Many respondents considered juridical assistance to be necessary for the use of enforcement measures in their units. In many units, however, there are no specialized lawyers for food control issues, resulting in food control officials needing to deal with food safety legislation as well as the administrative process. Previously, shortcomings in the implementation of administrative procedures and fulfilment of good governance have been identified among Finnish control authorities (Lepistö et al., 2009). Since good governance is a precondition for the efficacy of enforcement measures and official food control, as it safeguards the legitimacy of the decisions and the removal of health hazards (Lepistö et al., 2009), adequate training in administrative skills and sufficient juridical assistance for food control officials should be ensured.

In the vast majority of both enforcer and non-enforcer units, jurisdiction to use enforcement measures was delegated from the municipal body to the food control unit, either to the head or to the inspectors. If the decisions can be made in the unit, instead of taking it before a municipal body, the initiation of an enforcement process would be more smooth and its threshold lower, which probably explains why the delegation appeared as a selective factor among the enforcer and non-enforcer inspectors in the CHAID analysis. Although municipal politicians' attempts to influence the use of enforcement measures appear to be only occasional, political 
interests or views of the members of the municipal authority bodies may, in some cases, diverge from the interpretation of the food control officials. To ensure equal treatment of the FBOs and safeguard effective intervention in food safety violations, it is important that the decisions are made based on the legislative requirements, independently of political or business interests.

Inspectors appear to feel confident in the support of the head of their unit and their colleagues. However, the head's expertise in food hygiene, food safety legislation and administrative issues was assessed more positively by the inspectors of enforcer units than by the inspectors of non-enforcer units. Use of enforcement measures in the unit likely develops the head's knowledge and certainty about the process, but, on the other hand, having a more experienced head may promote the use of enforcement measures in the unit. In addition, the inspectors of the units led by a veterinarian evaluated the expertise of the head more positively than the inspectors of nonveterinarian-led units. This may result from the strong emphasis on food safety and administrative procedures in Finnish veterinary education (Faculty of Veterinary Medicine, 2016). Regardless of the education, the head's good knowledge and conversance with food safety issues and enforcement procedures likely promote inspectors' capabilities of using enforcement measures and should therefore be maintained and further developed in all units. enforcement measures appears to be of concern for many food control officials. The non-enforcer inspectors' significantly stronger perceptions of impairment of the cooperation may decrease their willingness to use enforcement measures. To avoid unequal treatment of the FBOs and to ensure compliance, the use of control measures should be uniform and consistent across the control units and the inspectors, despite officials' personal perceptions. As previously reported among restaurant business operators (RBOs), the interaction between the RBO and the inspector affects the RBOs' attitudes towards food hygiene and official food control (Läikkö-Roto \& Nevas, 2014). In difficult control situations and despite the compulsory nature of the enforcement decisions, cooperative 
skills of the food control official are of particular importance and should be enhanced by appropriate training provided for the officials.

FBOs' lack of understanding of the enforcement decision and the required actions was highlighted among the FBO-related challenges perceived by the food control officials. As previously reported by Fairman and Yapp (2005), especially small-scale FBOs have difficulties in distinguishing the difference between administrative documents and other letters received from the authorities. If the FBOs do not understand the legislative difference between a notification and an order, the efficacy of using enforcement measures is impaired. Proper reasoning behind the control measures should be emphasized as it has been reported to help FBOs understand the relevance of the food safety violations detected by the inspector (Nevas, Kalenius, \& Lundén, 2013) and to improve the correction of non-compliance in restaurants (Läikkö-Roto \& Nevas, 2014).

Cultural and language-related challenges in communication with the FBOs were a stated concern of a few respondents and, along with globalization and increasing immigration, are likely to become more and more emphasized in all public affairs. Officials' understanding of cultural diversity and their skills in multicultural settings are crucial for efficient delivery of services to diverse target groups (Rice, 2007). For instance, FBOs with an immigrant background may benefit from special assistance, e.g. translated guidelines on the national legislative requirements. To enhance food control officials' abilities to communicate with FBOs from diverse cultural backgrounds, cultural competency skills should be incorporated in officials' vocational education and further training. The influence of multiculturalism on compliance and interactions between officials and FBOs would also be interesting research topics.

Although enforcement measures were considered to have improved food safety and to be necessary tools for official food control, a notable number of the respondents seems to be somewhat dissatisfied with the efficacy of their use. In our previous study, the median duration of enforcement processes until verified correction of non-compliance was almost two months but 
ranged from one day to nearly three years (Kettunen et al., 2015). The long durations of enforcement processes are partly explained by the administrative stages of the procedure, but may also, as indicated by our results, reflect a lack of routine, inadequate guidance and unclear operational procedures in the units, decreasing the effectiveness of the procedure. The perceived slowness of the enforcement process and the lack of substantial consequences are the most likely reasons for approximately half of the respondents wishing for stricter interventions in the event of a severe non-compliance. More regular reports of severe food safety violations to the police by food control authorities could improve the preventive aspect of official food control (Lepistö \& Hänninen, 2011). Moreover, in Denmark, for instance, food control authorities may impose an administrative fine as a control measure in response to FBO's non-compliance (FVO, 2013; The Danish Veterinary and Food Administration, 2016). As suggested by many respondents and also previously discussed by Lepistö (2008) as an option to enhance the efficacy of control actions, the preconditions and potential of food control units issuing FBOs fines could be investigated in Finland as well. In addition, the costs and officials' working hours spent on enforcement procedures are unknown and would be an important topic for future research.

It can be deliberated whether non-enforcer units have been more effective in enforcing food safety regulations by using soft control methods instead of enforcement measures. Considering the perceived arduousness and slowness of enforcement process, it may be more efficient to get non-compliances corrected by using negotiation and guidance. However, soft control measures are not always adequate to remove severe or recurrent food safety hazards. In most cases in which enforcement measures have been used, the FBO had not corrected the food safety violations although a request to correct the non-compliance had been given before initiating an enforcement process (Kettunen et al., 2015). Thus, it is important that food control authorities have the preparedness to use enforcement measures when needed. 
The ultimate aims of official food control are to prevent foodborne illness among consumers by ensuring food safety and to safeguard FBOs' equal operating conditions by highquality and impartial enforcement (EC No 882/2004; Food Act, 2011). However, direct impacts of inspections and the use of enforcement measures on the occurrence of foodborne illnesses are difficult to determine. For example, conclusions of the studies on correlations between inspection results and foodborne illness are conflicting (e.g. Cruz, Katz, \& Suarez, 2001; Jones, Pavlin, LaFleur, Ingram, \& Schaffner, 2004; Simon, Leslie, Run, \& Jin, 2005). On the other hand, a study in Finland has indicated that food control units' resources and level of official food control are related to the number of food- or waterborne outbreaks in the units' areas, highlighting the significance of a well-functioning official food control system for public health (Tähkäpää, Maijala, Hörman, Poutiainen-Lindfors, \& Korkeala, 2008). Yet additional research is needed to detect measurable indicators to link official food control performance to public health.

Comparison of the proportion of units using enforcement measures in this study (86.7\%) with that of our previous study in 2008-2011 (65.6\%) (Kettunen et al., 2015) suggests an increase in the use of enforcement measures in Finland. As responses were received from the majority of the units, presumably because local food control officials perceive the development of the use of enforcement measures as important, the representativeness of the study can be considered to be good. Reasons for regional variation in the units' response rates are unclear, but the low median of labour resources of non-respondent units suggests that there may be non-enforcer units among non-respondents, possibly explaining why officials from those units were not eager to respond. Conclusively, our findings indicate that several challenges remain and should be considered in unifying and developing use of enforcement measures.

\section{Conclusions}


More than $40 \%$ of the local food control officials perceived that enforcement measures are not

461

462

463

464

465

466

467

468

469

470

471 the large ones may unify the practices and promote the capabilities to use enforcement measures in 472 all units.

always used in their unit when needed to ensure food safety. Large units had used enforcement measures more commonly than small units and appear to have better availability of practical prerequisites, such as guidelines and templates, for using enforcement measures. In many units, however, a lack of routine, uncertain practices and laboriousness of the administrative procedure pose challenges for using enforcement measures. To harmonize practices and to ensure that use of enforcement measures is a true option in all units, further development and effective adoption of operating procedures to implement enforcement measures are essential. To overcome the hurdles to use enforcement measures and to improve food control officials' confidence in using enforcement measures, specific training on the administrative procedures and reasoning of the decisions with a practical approach and example cases should be provided. Moreover, merging the small units with

\section{Acknowledgements}

475 We sincerely thank all participating local food control units and officials for their cooperation. The 476 study was supported by the Finnish Cultural Foundation and the Finnish Foundation of Veterinary 477 Research.

479 References

480 Cruz, M. A., Katz, D. J., \& Suarez, J. A. (2001). An assessment of the ability of routine restaurant 481 inspections to predict food-borne outbreaks in Miami-Dade County, Florida. American Journal of 482 Public Health, 91(5), 821-823. doi: 10.2105/AJPH.91.5.821. 
EC No 882/2004. Regulation (EC) No 882/2004 of the European Parliament and of the Council of 29 April 2004 on official controls performed to ensure the verification of compliance with feed and food law, animal health and animal welfare rules. http://eur-lex.europa.eu/legalcontent/EN/TXT/PDF/?uri=CELEX:02004R0882-20140630\&qid=1461658401732\&from=FI. Accessed 26.4.2016.

European Commission. (2013). Report from the Commission to the European Parliament and to the Council on the overall operation of official controls in the Member States on food safety, animal health and animal welfare, and plant health. $\operatorname{COM}(2013) 681$ final. http://eur-lex.europa.eu/legalcontent/EN/TXT/PDF/?uri=CELEX:52013DC0681\&from=en. Accessed 26.8.2016.

Faculty of Veterinary Medicine. (2016). Structure of verinary curriculum.

http://www.vetmed.helsinki.fi/english/studying/curriculum.html\#. Accessed 29.8.2016.

Fairman, R., \& Yapp, C. (2005). Enforced Self-Regulation, Prescription, and Conceptions of Compliance within Small Businesses: The Impact of Enforcement. Law \& Policy, 27(4), 491-519.

Food Act. (2011). Food Act 23/2006, amendment 352/2011.

http://www.finlex.fi/fi/laki/kaannokset/2006/en20060023.pdf. Accessed 26.4.2016.

FVO. (2013). Final report of an audit carried out in Denmark from 08 to 12 April 2013 in order to evaluate the systems put in place to give effect to the provisions of art. 8(3) of regulation 882/2004 of the European Parliament and of the Council. DG(SANCO) 2013-6857 - MR FINAL. http://ec.europa.eu/food/fvo/act_getPDF.cfm?PDF_ID=10777. Accessed 20.10.2016.

FVO. (2014). Final report of an audit carried out in Finland from 11 to 21 March 2014 in order to evaluate the food safety control systems in place governing the production and placing on the 
market of poultry meat and products derived therefrom. DG(SANCO) 2014-7155 - MR FINAL. ec.europa.eu/food/fvo/act_getPDF.cfm?PDF_ID=11415. Accessed 20.10.2016.

Hampton, P. (2005). Reducing administrative burdens: Effective inspection and enforcement. $H M$ Treasury.

Hutter, B.M., \& Amodu, T. (2009). Risk regulation and compliance: Food safety in the UK. London School of Economics and Political Science.

IMPEL. (2015). Challenges in the practical implementation of EU environmental law and how IMPEL could help overcome them. European Union Network for the Implementation and Enforcement of Environmental Law, final report: 23 March 2015. http://impel.eu/wpcontent/uploads/2015/07/Implementation-Challenge-Report-23-March-2015.pdf. Accessed 15.12.2016.

Johnson, R.B., Onwuegbuzie, A.J., \& Turner, L.A. (2007). Toward a definition of mixed methods research. Journal of Mixed Methods Research, 1(2), 112-133. doi: 10.1177/1558689806298224.

Jones, T. F., Pavlin, B. I., LaFleur, B. J., Ingram, L. A., \& Schaffner, W. (2004). Restaurant Inspection Scores and Foodborne Disease. Emerging Infectious Diseases, 10(4), 688-692. doi: https://dx.doi.org/10.3201/eid1004.030343.

Kettunen, K., Nevas, M., \& Lundén, J. (2015). Effectiveness of enforcement measures in local food control in Finland. Food Control, 56, 41-46. doi: 10.1016/j.foodcont.2015.03.005. food control. Food Control, 61, 172-179. doi: $\underline{\text { http://dx.doi.org/10.1016/j.foodcont.2015.09.043. }}$ 

inspection processes of food control officials and efficacy of official controls in restaurants in Finland. Food Control, 57, 341-350. doi: 10.1016/j.foodcont.2015.03.053. Läikkö-Roto, T., \& Nevas, M. (2014). Restaurant business operators' knowledge of food hygiene and their attitudes towardofficial food control affect the hygiene in their restaurants. Food Control, 43, 65-73. doi: 10.1016/j.foodcont.2014.02.043.

530 Lepistö, O. (2008). The principle of good governance in environmental health compulsory actions.

531 Helsinki, Finland: Department of Food and Environmental Hygiene, University of Helsinki,

532 dissertation.

533 Lepistö, O., \& Hänninen, M.-L. (2011). Effects of legal aspects on the use of compulsory

534 procedures in environmental health and food control. Journal of Environmental Health Research, $53511,127-134$.

536 Lepistö, O., Nevas, M., \& Hänninen, M.-L. (2009). The realisation of the principle of good 537 governance in compulsory actions in environmental health and food control. Arch Lebensmittelhyg, $53860(5), 148-151$.

539 Luukkanen, J., \& Lundén, J. (2016). Compliance in slaughterhouses and control measures applied 540 by official veterinarians. Food Control, 68, 133-138. doi: 10.1016/j.foodcont.2016.03.033.

541 Nevas, M., Kalenius, S., \& Lundén, J. (2013). Significance of official food control in food safety:

542 Food business operators' perceptions. Food Control, 31, 59-64.

543 O'Cathain, A., \& Thomas, K.J. (2004). "Any other comments?" open questions on questionnaires 544 a bane or a bonus to research? BMC Medical Research Methodology, 4, 25. doi: 10.1186/1471$545 \quad 2288-4-25$. 
546 Rice, M.F. (2007). A postmodern cultural competency framework for public administration and

547 public service delivery. Intl Jnl Public Sec Management, 20(7), 622-637. doi:

$548 \quad 10.1108 / 09513550710823524$.

549 Simon, P. A., Leslie, P., Run, G., \& Jin, G. Z. (2005). Impact of restaurant hygiene grade cards on

550 foodborne-disease hospitalizations in Los Angeles County. Journal of Environmental Health, 67(7),

55132.

552 The Danish Veterinary and Food Administration. (2016). Inspection of food establishments.

553 https://www.foedevarestyrelsen.dk/english/inspection/inspection_of_food_establishments/pages/def

554 ault.aspx. Accessed 22.8.2016.

555 Tähkäpää, S., Maijala, R., Hörman, A., Poutiainen-Lindfors, U., \& Korkeala, H. (2008). Reasons

556 behind inadequate local food control resources. Food Control, 19(4), 403-411. doi:

557 http://dx.doi.org/10.1016/j.foodcont.2007.04.020 


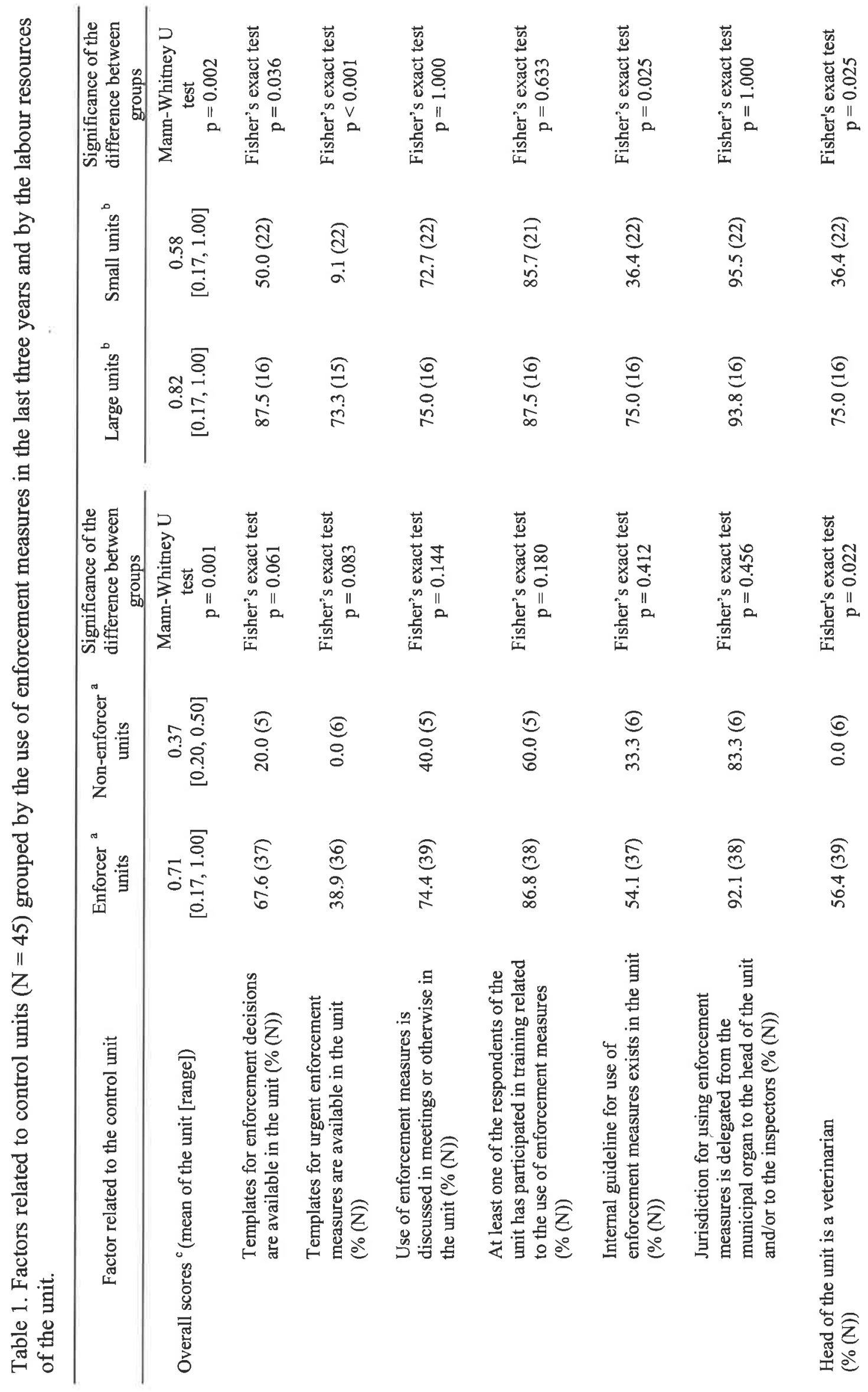




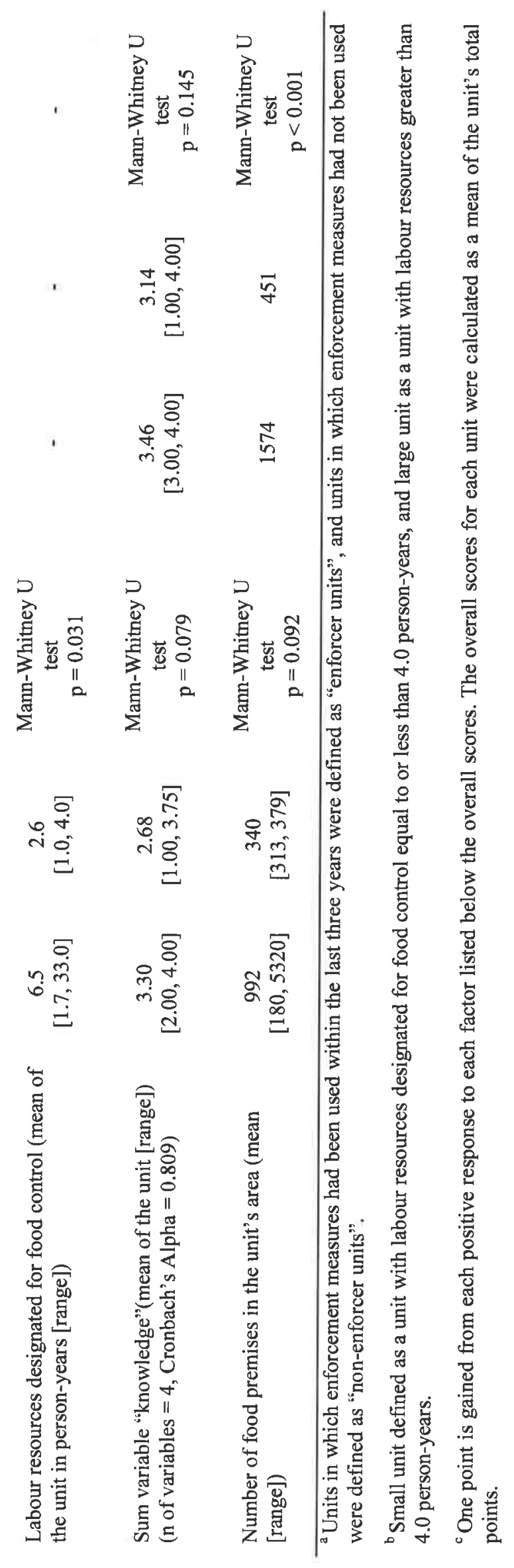


Table 2. Inspectors' $(\mathrm{N}=101)$ perceptions of their expertise and attitudes towards the use of enforcement measures grouped by whether they have used enforcement measures.

\begin{tabular}{|c|c|c|c|}
\hline \multirow{3}{*}{ Claim } & \multicolumn{2}{|c|}{$\begin{array}{l}\text { Use of enforcement measures by the } \\
\text { inspector }^{\mathrm{a}} \\
\%(\mathrm{~N})\end{array}$} & \multirow{3}{*}{$\begin{array}{l}\text { Significance of the } \\
\text { difference between } \\
\text { groups } \\
\text { (Fisher's exact test) }\end{array}$} \\
\hline & $\begin{array}{l}\text { Enforcer } \\
\text { inspectors }\end{array}$ & $\begin{array}{l}\text { Non-enforcer } \\
\text { inspectors }\end{array}$ & \\
\hline & $\begin{array}{c}\text { Totally or } \\
\text { somewhat agree }\end{array}$ & $\begin{array}{c}\text { Totally or } \\
\text { somewhat agree }\end{array}$ & \\
\hline
\end{tabular}

Expertise

I have sufficient knowledge of administrative processes $^{b}$

It is clear to me when using enforcement measures is reasonable ${ }^{\mathrm{b}}$

I have sufficient knowledge of food hygiene and safety ${ }^{\text {b }}$

I have sufficient knowledge of food safety legislation ${ }^{b}$

$90.2(61)$

$88.7(62)$

$85.7(35)$

$p=0.752$

Challenges

Use of enforcement measures impairs the cooperation between the inspector and the FBO $^{\text {b }}$

I would get support from my superior in using enforcement measures

I would get support from my colleagues in using enforcement measures

$3.3(61)$

$63.9(36)$

$\mathrm{p}=0.053$

$74.3(35)$

$\mathrm{p}=0.088$

$81.1(37)$

$p=0.229$

The document management systems of our control unit are easy to use ${ }^{b}$

Enforcement processes are too slow for ensuring food safety

Enforcement measures are laborious

Enforcement measures are unnecessary
$79.4(34)$

$p=0.026$

$p=0.228$

$82.6(35)$

$86.1(36)$

$\mathrm{p}=0.151$

$91.9(37)$

$p=0.295$

$42.3(26)$

$p=0.350$

$87.9(33)$

$p=0.401$

$91.7(36)$

$p=0.667$

$2.6(38)$

$p=1.000$

\footnotetext{
"Inspectors who had used enforcement measures themselves are defined as "enforcer inspectors", and inspectors who had not used enforcement measures themselves are defined as "non-enforcer inspectors".

${ }^{b}$ Claim used as a predicting variable in the CHAID analysis explaining the use of enforcement measures by the inspectors.
} 
Figure 1

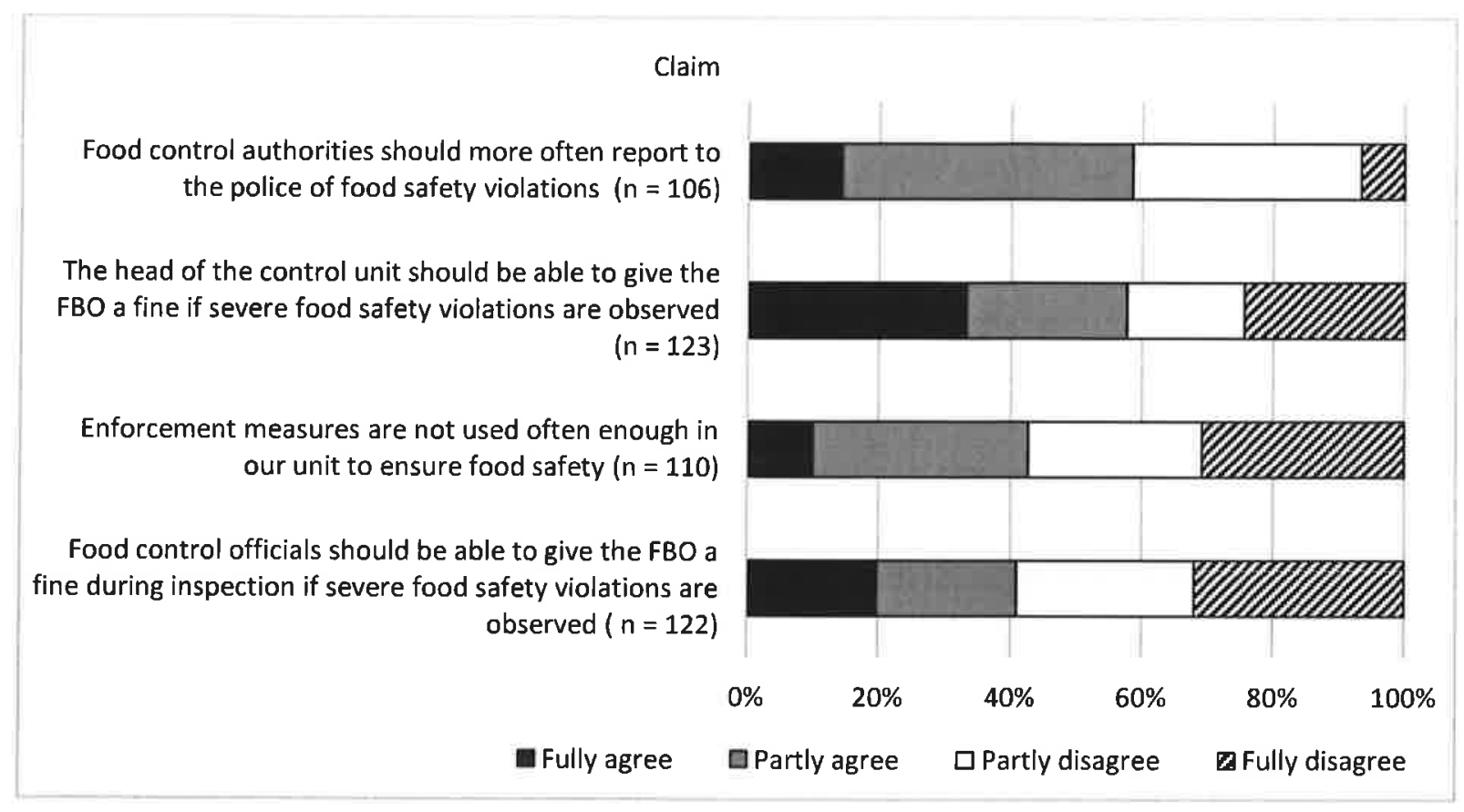

Figure 1. 


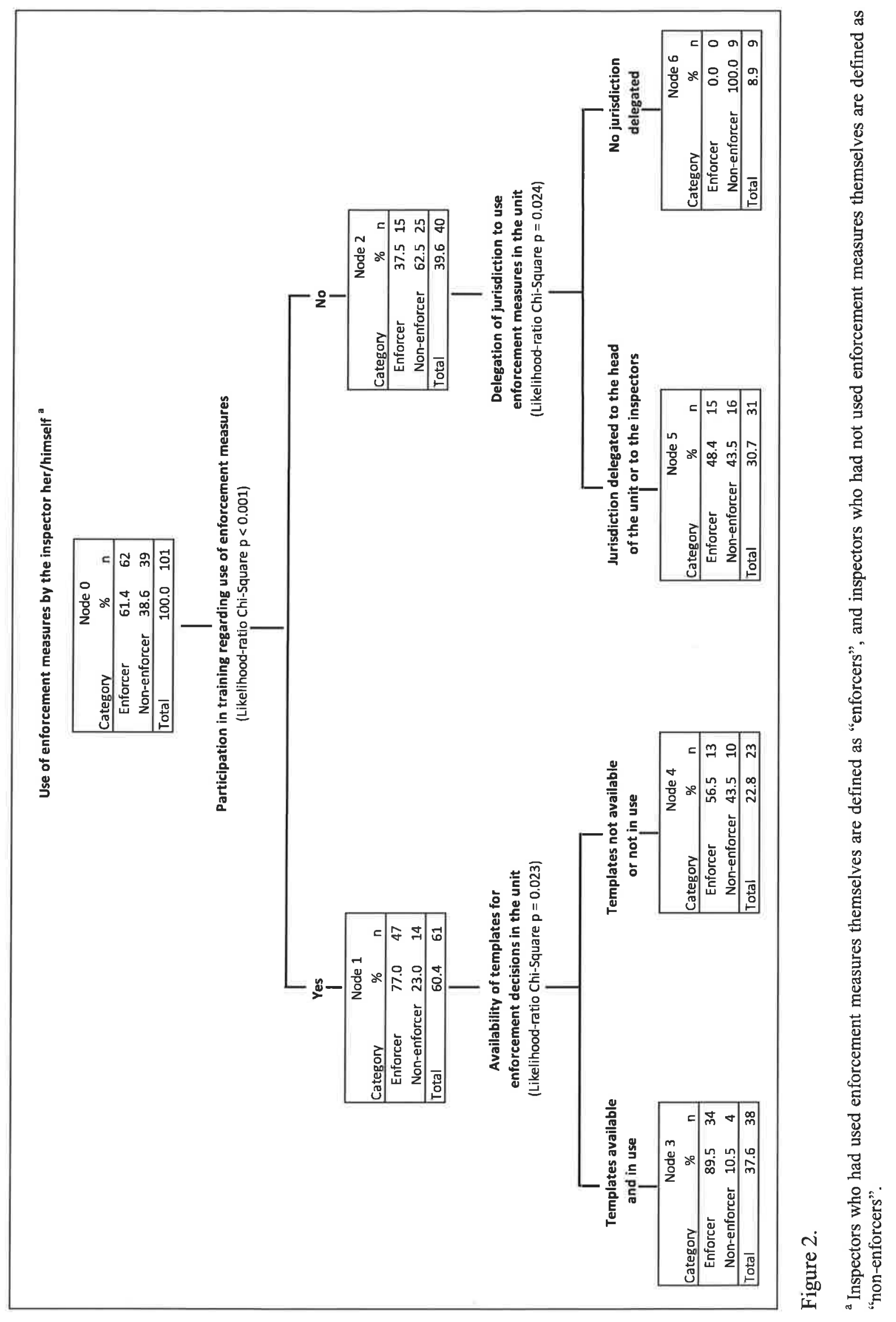


Figure 1. Respondents' $(\mathrm{N}=129)$ opinions about the adequacy of using enforcement measures in their unit and the need for stricter measures to intervene in food safety violations.

Figure 2. Classification tree created with a CHAID analysis for the factors explaining the use of enforcement measures by the inspectors $(\mathrm{N}=101)$.

a Inspectors who had used enforcement measures themselves are defined as "enforcers", and inspectors who had not used enforcement measures themselves are defined as "non-enforcers". 


\section{Highlights}

- Enforcement measures are not used often enough in the opinion of $43 \%$ of the officials.

- Lack of routine and uncertain practices impede the use of enforcement measures.

- Large units seem to have better practical prerequisites for using enforcement measures.

- Impairment of cooperation with FBO due to enforcement measures concerns officials.

- Specific training on using enforcement measures should be provided for officials. 
